Pettigrew, T.F. (1998). Intergroup contact theory. Annual Review of Psychology, 49, 65-85. doi:10.1146/annurev.psych.49.1.65

Ruggs, E. N., Hebl, M. R., Rabelo, V. C., Weaver, K. B., Kovacs, J., \& Kemp, A. S. (2016). Baltimore is burning: Can I-O psychologists help extinguish the flames? Industrial and Organizational Psychology: Perspectives on Science and Practice, 9(3), 525-547.

Vasey, M. W., Harbaugh, C. N., Buffington, A. G., Jones, C. R., \& Fazio, R. H. (2012). Predicting return of fear following exposure therapy with an implicit measure of attitudes. Behaviour Research and Therapy, 50, 767-774. doi:10.1016/j.brat.2012.08.007

\title{
Additional Ideas for Putting Out the Flames
}

Rick Jacobs, Jean Phillips, and Stan Gully

Pennsylvania State University

It is hard to argue with the central thesis of the focal article (Ruggs et al., 2016) that industrial-organizational (I-O) psychology has much to offer police departments in helping them meet their mission. As an example, the Los Angeles Police Department provides a clear statement that is representative of most police agencies:

\footnotetext{
It is the mission of the Los Angeles Police Department to safeguard the lives and property of the people we serve, to reduce the incidence and fear of crime, and to enhance public safety while working with the diverse communities to improve their quality of life. Our mandate is to do so with honor and integrity, while at all times conducting ourselves with the highest ethical standards to maintain public confidence. (Los Angeles Police Foundation \& LAPD, 2016)
}

The mission statement encompasses a wide range of responsibilities and associated tasks, competencies, and actions. Although much of what I-O psychology has accomplished over the past 100 years in the way of excellence in selection, training, performance management, leadership, and motivation can be directly linked to challenges these organizations face, it is a major undertaking to fit what we know into an integrated set of programs that can not only help departments succeed but also simultaneously help them avoid tragedies. Highly visible examples of police misconduct from across the country have filled the news media. The deaths of Freddie Gray (Baltimore, MD), Michael Brown, Jr. (Ferguson, MO), Eric Garner (Staten Island, NY), Laquan McDonald (Chicago, IL), and unfortunately many more represent isolated but extreme problems in implementing the police mission. In reading "Baltimore Is Burning," four questions emerged and should be

Rick Jacobs, Department of Psychology, Pennsylvania State University; Jean Phillips and Stan Gully, School of Labor and Employment Relations, Pennsylvania State University.

Correspondence concerning this article should be addressed to Rick Jacobs, Department of Psychology, Pennsylvania State University, University Park, PA 16802. E-mail: rick.jacobs@ebjacobs.com 
addressed if we, as I-O psychologists, are to make contributions to police functioning.

\section{Who Is in Charge?}

The article calls for more research and greater application of what we know to various issues facing police departments, including selection, training, performance management, and leadership. All well and good, but as an example, the problem of racial bias in policing requires a coordinated attack in all these areas, and someone needs to take charge. An integrative effort will require a very competent program manager who both understands the complex world of a police department and can manage a team of professionals bringing in diverse solutions across a variety of disciplines, including our own. It is one thing to have research based answers, but it is another to turn those into meaningful interventions in an environment where outsiders are often viewed with suspicion and change is often difficult to enact.

There is also a need to determine how such a program will be funded, from the basics of who will pay for training program delivery and developing validated processes for selection and promotion to ongoing and much needed periodic updating of training. The development of these initiatives along with the personnel necessary to run them competently all requires resources that are usually beyond the operating budgets of most police departments. There is also the issue of officer time-currently departments struggle with cost overruns because of personnel shortages and the use of overtime. More training, a clear need, will exacerbate the cost of daily operations. Funding becomes front and center for program success, and I-O psychologists have to grapple with this reality.

It is critical that a careful plan including identifying key personnel and outlining the funding mechanisms that can foot the bill is put into place if we are ever to have an opportunity to bring what we know to bear on the various issues. This goes well beyond the scope of most police agencies and implicates a national response to help all departments. The President's Task Force on 21st Century Policing (2015) is a positive step in that direction, including the funding calls to support such initiatives contained in their final report.

\section{What Is the Role of Training?}

The authors' ideas for leveraging I-O psychology's deep understanding of developing, executing, and evaluating effective training programs are very good. There is every reason to believe that racial bias could be reduced in many people through the development and implementation of the right training interventions. 
Simulations to teach officers about their own race-based shooter biases and diversity training are good ideas, as well as education on current tensions between officers and citizens and their impact on trust and potential behavior toward officers. Conflict resolution training focused on interracial encounters, cultural sensitivity training, and racial bias reduction training is also highly relevant to this opportunity for I-O psychology to have a positive influence.

In addition to the authors' numerous training suggestions, including more White aggressors in the training simulations and training officers to associate a wider variety of physical characteristics with different races to reduce stereotyping could also help to reduce racial bias and stereotyping (Sim, Correll, \& Sadler, 2013). Interestingly, Sim et al. (2013) found experts and police officers were less likely than novices to be influenced by a stereotypeaccessibility manipulation in lethal force training. However, training did not eliminate bias when base rates of race were related to incidents of being armed. This potentially creates a negative cycle. If minority suspects behave more aggressively toward officers because they expect officers to act more aggressively toward them, then this will prompt more aggressive officer responses and stimulate more aggressive civilian responses. Training officers about the key role of trust and about how to quickly and positively influence others' trust could be beneficial. Conversely, if training promotes the utility of racial cues in choosing to use lethal force it may exacerbate the situation.

One aspect of training that deserves careful consideration is transfer. If trainees don't apply what they learn or do not continue to use the acquired knowledge and skills over time then the training intervention will falter regardless of its initial success. Factors that affect transfer include managerial support, peer support, and opportunity to use learned capabilities (Noe, 2013). These contextual factors will strongly shape how and when training is transferred to reduce bias when interacting with the community. I-O psychologists can help law enforcement agencies ensure that training to address bias and diversity-related issues exhibits both generalization and maintenance over time, in part by creating a culture that supports both training and transfer. The culture of the law enforcement unit within which transfer is occurring must be considered, and periodic booster sessions are necessary to enhance the effectiveness of the training programs. Additionally, law enforcement personnel face unusually large amounts of stress in the performance of their duties, which is known to impair decision-making effectiveness. Training and support to mitigate the negative effects of stress may also help to improve officer effectiveness.

One important feature of any training program is determining its halflife. "Unlearning" is a likely outcome of police training initiatives as officers continue to perform their jobs on a day-to-day basis. In many instances 
initial training is all a department can afford, so follow-up training simply does not exist. As an example, Fachner and Carter (2015) note that Philadelphia police officers "do not receive regular, consistent training on the department's deadly force policy" (p. 4). Similar to the requirement to "recertify" on the shooting range, various types of training, especially those involving the reduction of bias, need to occur on a regular schedule with officers returning at set time periods.

\section{Are Current Selection Processes Helping or Hurting?}

Current rhetoric on selection in police organizations has been heating up. All you have to do is turn on the TV and listen to the politicians including Bernie Sanders who keep saying our police departments have to reflect the communities they serve. It is hard to disagree with that point, but it is difficult to make that a reality. It's important to note that progress has been made. According to the Bureau of Justice Statistics (2015), in 2013 the percentage of police officers who were members of racial or ethnic minority groups was nearly double that of the late 1980s. However, there is still much room for improvement.

Competitive testing has been, overall, a positive step for public safety jobs. The problem is that these are good jobs, and they are attractive to many more people than departments can hire. Demand for these jobs is high, sometimes exceeding 100 applicants per vacancy. When the selection ratio gets very small then even very small differences in test scores cause adverse impact against Black and often Hispanic candidates. This is largely due to the use, even on a limited basis, of cognitive ability assessment as part of the selection system. I-O psychology has spent decades minimizing difference in these testing programs with a great deal of success. We have seen the racebased differences on tests drop from 1.0 standard deviation to in some cases under 0.3. One example can be seen in the work by Cascio, Jacobs, and Silva (2010). Although this represents substantial movement in a positive direction, it is not enough if selection ratios continue to range from $1 / 20$ to $1 / 100$. For example, if the selection ratio is $10 / 100(10 \%)$ and the standardized difference is .3 , then the selection ratio for the minority group will be about $5.7 \%$, nearly half that of the majority group.

Quite simply the Civil Rights Act of 1991 is the biggest barrier to solving the problem of underrepresentation. Prior to its enactment many departments used a system of dual list or multilist selection. Selecting top down within groups eliminated or nearly eliminated differential selection ratios resulting from mean differences on predictors while generally maintaining the validity of prediction relative to top-down selection (Gottfredson, 1994; Sackett \& Wilk, 1994). This approach is often labeled quota hiring, but in fact, it is the most effective answer to solving the problem of 
representation (Silva \& Jacobs, 1993) and maintaining high levels of performance. Details are beyond the scope of current discussion, but the interested reader is referred to the sources noted above. Although multilist selection is a "good" practical solution, it is illegal under current law. Here, more creative solutions need to be developed and implemented, and a fundamental decision regarding the importance of racial representation must be made.

The authors' suggestions in the area of improving screening procedures to better assess bias are also important, but the most influential personality and individual differences on racial bias and on the ability to overcome racial bias particularly under stress need to be better identified. People behave differently under stress, and it is important to consider this in terms of bias in decision making. Perhaps characteristics including empathy, humility, tolerance, global openness, openness to racial diversity (other-group orientation), and others will be found to be related to racial bias and racial bias under stress. If so, these and other related characteristics can be effectively used in sourcing, recruiting, and selection decisions. Additionally other types of assessments such as those advocated by James and colleagues (2005) to assess aggression have great potential.

As discussed by Bell (1980), there may be different types of racists, including those who are socially misinformed and those with an underlying personality disorder. Each results in a different potential to overcome racial bias. A socially misinformed racist's beliefs are the result of internalized socialization and are due to ignorance, so these individuals are more likely to be successfully influenced to adopt a less biased value system. Racists due to a personality disorder, on the other hand, are unlikely to be influenced by a training intervention unless it addresses the personality issue directly. For example, Bell (1978) noted that treating underlying narcissistic personality disorders through empathy training "relieved the symptoms of racism" (p. 90), regardless of the person's race. Because narcissists are known to have a reduced capacity for empathy, this suggests the potential for aptitudetreatment interactions to influence the effectiveness of racial bias awareness and empathy training. Room for these types of assessments exists across the selection process from initial testing through background investigation and professionally conducted psychological screening.

\section{Can We Point to Examples Where Programs Are Working?}

There is no doubt that counterproductive behaviors occur in all organizations. Lau, Au, and Ho (2003) provided a meta-analysis pointing to antecedents of these behaviors across a variety of organizations, and Smoktunowicz et al. (2015) analyzed data on counterproductive behaviors specific to policing. Other examples can be easily found in the I-O literature. These 
studies help pinpoint problems and areas for developing programs to help provide solutions.

Several important tools in the toolbox of I-O psychology could be helpful. We are good at conducting surveys and benchmarking. There are thousands of police agencies across the country. The U.S. Bureau of Justice Statistics' 2008 Census of State and Local Law Enforcement Agencies listed 1,117 law enforcement agencies in Pennsylvania alone, employing 27,413 sworn police officers. Many police departments are engaged in meaningful programs to address the issues they face. We need to begin cataloging those programs, identifying those that work, and making the specifics of those programs known to a broader audience. How do the nature of the human resource management (HRM) practices, supervision, culture, and other factors differ between police departments with greater and less success in the area of racial bias? We need a demonstration project to fit many of these effective programs together into an integrated whole and test its overall efficacy. Such an approach will require the aforementioned program manager, a team of multidisciplinary experts, and external funding.

There appears to be optimism for such an approach actually coming to fruition. In September 2014, Attorney General Eric Holder announced that the Department of Justice awarded the National Network for Safe Communities, through John Jay College of Criminal Justice, a 3-year, \$4.75 million grant to launch a National Initiative for Building Community Trust and Justice (https://trustandjustice.org). In March of 2015, the Department of Justice's Office of Public Affairs identified the six target sites: Birmingham, AL; Fort Worth, TX; Gary, IN; Minneapolis, MN; Pittsburgh, PA; and Stockton, $\mathrm{CA}$. As this program unfolds, it will likely provide examples of effective interventions. More of us need to be part of this and other efforts. Likewise, the President's Task Force on 21st Century Policing (2015) provided an overarching recommendation that "The President should support and provide funding for the creation of a National Crime and Justice Task Force to review and evaluate all components of the criminal justice system for the purpose of making recommendations to the country on comprehensive criminal justice reform" (p. 7). More of us need to be involved in these types of initiatives as well.

In addition to the four key questions discussed above, two additional issues emerged as we thought and wrote about how I-O psychology can help to extinguish the fire.

\section{Do Different Aspects of the Human Resource Management (HRM) System Within Police Organizations Successfully Interact?}

Not surprisingly given our backgrounds, we believe that it is important to take an integrated perspective. We know that our HRM systems must be 
aligned horizontally and vertically (Wright \& McMahan, 1992) with the dayto day functioning and the mission of an organization. Continued improvements in effective, race-neutral policing will depend on integrated, aligned organizational policies and practices and climate interventions. In terms of horizontal alignment, training cannot fix poor recruitment and selection practices, and excellent recruitment practices will not resolve anything if poor or biased training exists or if training is simply not part of the equation. If the socialization and reward systems are misaligned with the goal of ensuring effective and unbiased action by law enforcement personnel then the selection and training systems will fail regardless of quality.

Vertical alignment is the connection of HRM strategies, policies, and practices to the broader goals and strategies of the organization. But what should be those goals and strategies? According to the presidential task force, there are multiple pillars to an effective future for law enforcement, including building trust and legitimacy by acting in procedurally just ways, actively building positive relationships with members of the community, and engaging and educating communities in a dialogue about transparency, accountability, and privacy (President's Task Force on 21st Century Policing, 2015). If these are the goals, then we will need to help organizations to align their recruiting, selection, training, socialization, reward, and performance feedback systems with the goals of connecting to the community and engaging in procedurally just and transparent behaviors.

I-O psychologists should examine practices and interventions that we put into place within the context of the broader system. Often we focus on improving a specific training intervention, increasing the validity of a selection system, or reducing adverse impact, but as noted above, we have to align all components in order to have lasting impact. This is different from thinking about finding and developing people who can handle a gun effectively, complete paperwork accurately, and conduct investigations professionally. These are no small tasks to accomplish, but they are worthy of pursuit.

\section{Public Relations and Communication}

I-O psychology has an opportunity to help defuse the heated rhetoric that exists by educating the public regarding the challenges faced by law enforcement personnel, highlighting successes, and building relationships between communities and the agencies that exist to serve and protect them.

In 2014, there were approximately 800,000 police or sheriff patrol officers and detectives (Bureau of Labor Statistics, 2014), and in 2011 they had over 60 million encounters with the public over the course of a year (Bureau of Justice Statistics, 2013). Clearly most law enforcement personnel have high numbers of interactions with the public without incident. Based on statistics, bias exists, but it is not as rampant as the media would have us 
believe. Black drivers (13\%) were slightly more likely than White (10\%) and Hispanic (10\%) drivers to be pulled over by police in a traffic stop. Blacks, Whites, and Hispanics were equally likely to be stopped in a street stop (less than $1 \%$ each). We can see that there is evidence of differential traffic stop rates, but perhaps it is not as great as one might imagine. A large majority of people believed police behaved properly in these interactions, and less than $5 \%$ of the people who believed police did not behave properly filed a complaint (Bureau of Justice Statistics, 2013). This is a huge number of potentially confrontational situations in which an appropriate resolution was achieved. This is not to say that bias or inappropriate behavior is nonexistent. Blacks were less likely than Whites and Hispanics to believe police behaved properly. Black (6.3\%) and Hispanic (6.6\%) drivers are nearly three times as likely as White drivers (2.3\%) to be searched (Bureau of Justice Statistics, 2011a). They are also less likely to have confidence in the ability of police to protect them from violent crime (President's Task Force on 21st Century Policing, 2015).

Additionally, deadly encounters do occur during arrests. In the period from 2003 to 2009, there were more than 4,800 arrest-related deaths, $95 \%$ of which were male. About $42 \%$ were White, $32 \%$ were Black/African American, and 20\% were Hispanic or Latino (Bureau of Justice Statistics, 2011b). On the basis of the media reports, one would be led to believe that arrestrelated deaths are much higher among non-White detainees but in fact, the opposite happens based on proportion of incidents. The probability that a Black/African American male may be killed by an officer could be explained by the level of violent crime in the community (Klinger, Rosenfeld, Isom, \& Deckard, 2016), but the probability of being Black, unarmed, and shot by police is about 3.5 times the probability of being White, unarmed, and shot by police (Ross, 2015). In Philadelphia, Black officers were more likely to shoot at unarmed Black suspects (11.4\%) than White officers were (6.8\%; Fachner \& Carter, 2015). Evidence suggests differential rates exist, but it is complex to understand.

Against this backdrop we find 48,315 officers were assaulted while performing their duties in 2014, which is a rate of about 9 per 100 sworn officers (Federal Bureau of Investigation, 2015). Officers regularly put themselves in harm's way, and for this privilege their median pay was about $\$ 57,000$ a year $\left(\mathrm{O}^{\star} \mathrm{Net}, 2016\right)$. The issue of assault on police officers is critical in understanding how implicit or explicit bias can translate into lethal force.

Blair et al. (2011) show that even well-trained officers operating in nearly ideal circumstances with their guns drawn and preaimed at a suspect cannot reasonably be expected to shoot before a suspect raises his or her gun from a downward position and fires. This means that officers need to react to threat before any action takes place and work to defuse the situation. It is in these 
milliseconds that the implicit, explicit, and other potential biases play out as the officer decides whether or not to deploy deadly force. Perceived threat and stress exert strong effects. I-O psychologists have a formidable amount of work before us. First, we need to better communicate to the public the challenging and deadly nature of law enforcement work and how well most officers are performing their duties to help defuse the situation. If officers feel embattled then they are more likely to take aggressive, even lethal action, when faced with a confrontation because they have no time to deliberate. Second, I-O psychologists must identify how to train officers to defuse confrontations while enabling them to make split-second life-or-death decisions with accuracy and without bias in these tense and potentially deadly confrontational encounters.

We agree with Ruggs et al. that I-O psychology has much to offer when it comes to effective policing, but knowledge in and of itself is not enough to make the difference. Much of what we have identified scientifically and implemented successfully is helpful, but much more is needed as our science and practice attempt to solve complex and political realities within modern police organizations. The Society for Industrial and Organizational Psychology and I-O psychologists should find ways to collaborate with criminologists, sociologists, cognitive psychologists, social workers, law enforcement professionals, and many others to find the best and most effective practices to rebuild the partnership between law enforcement and the communities they are intended to serve and protect. Only then will the flames in Baltimore and elsewhere have a chance of being truly extinguished.

\section{References}

Bell, C. C. (1978). Racism, narcissism, and integrity. Journal of the National Medical Association, 70(2), 89-92.

Bell, C. C. (1980). Racism: A symptom of the narcissistic personality. Journal of the National Medical Association, 72(7), 661-665.

Blair, J. P., Pollock, J., Montague, D., Nichols, T., Curnutt, J., \& Burns, D. (2011). Reasonableness and reaction time. Police Quarterly, 14(4), 323-343.

Bureau of Justice Statistics. (2011a). Police behavior during traffic and street stops, 2011. Retrieved from http://www.bjs.gov/content/pub/pdf/pbtss11.pdf

Bureau of Justice Statistics. (2011b). More than 4,800 arrest-related deaths reported from 2003 to 2009. Retrieved from http://www.bjs.gov/content/pub/press/pbtss11rpa11pr.cfm

Bureau of Justice Statistics. (2013). Study finds some racial differences in perceptions of police behavior during contact with the public. Retrieved from http://www.bjs.gov/content/pub/press/ pbtss11rpa11pr.cfm

Bureau of Justice Statistics. (2015). Percentage of local police officers who were racial or ethnic minorities nearly doubled between 1987 and 2013. Retrieved from http://www.bjs.gov/content/pub/press/ lpd13ppppr.cfm

Bureau of Labor Statistics. (2014). Police and detectives. Occupational outlook handbook. Retrieved from http://www.bls.gov/OOH/protective-service/police-and-detectives.htm 
Cascio, W. F., Jacobs, R. R., \& Silva, J. (2010). Validity, utility, and adverse impact: Practical implications from 30 years of data. In J. Outtz (Ed.), Adverse impact (pp. 271-288). New York, NY: Routledge.

Fachner, G., \& Carter, S. (2015). An assessment of deadly force in the Philadelphia police department. Washington, DC: Office of Community Oriented Policing Services.

Federal Bureau of Investigation. (2015, Fall). Uniform crime report: Law enforcement officers killed and assaulted, 2014. Retrieved from https://www.fbi.gov/about-us/cjis/ucr/leoka/2014/ officers-assaulted/assaults_topic_page_2014.pdf

Gottfredson, L. S. (1994). The science and politics of race-norming. American Psychologist, 49(11), 955-963.

James, L. R., McIntyre, M. D., Glisson, C. A., Green, P. D., Patton, T. W., LeBreton, J. M., ... Williams, L. J. (2005). A conditional reasoning measure for aggression. Organizational Research Methods, $8(1), 69-99$.

Klinger, D., Rosenfeld, R., Isom, D., \& Deckard, M. (2016). Race, crime, and the micro-ecology of deadly force. Criminology \& Public Policy, 15, 193-222. doi:10.1111/1745-9133.12174

Lau, V. C. S., Au, W. T., \& Ho, J. M. C. (2003). A qualitative and quantitative review of antecedents of counterproductive behavior in organizations. Journal of Business and Psychology, 18(1), 73-99.

Los Angeles Police Foundation \& LAPD. (2016). The mission statement of the LAPD. Retrieved from http://www.lapdonline.org/inside_the_lapd/content_basic_view/844

Noe, R. A. (2013). Employee training and development (6th ed.). New York, NY: McGraw-Hill/Irwin.

O^Net. (2016). Summary report for: 33-3051.01 - Police patrol officers. Retrieved from http://www. onetonline.org/link/summary/33-3051.01

President's Task Force on 21st Century Policing. (2015). Final report of the president's task force on 21st century policing. Washington, DC: Office of Community Oriented Policing Services.

Ross, C. T. (2015). A multi-level Bayesian analysis of racial bias in police shootings at the county-level in the United States, 2011-2014. PLoS One, 10(11), e0141854. doi:10.1371/journal.pone.0141854

Ruggs, E. N., Hebl, M. R., Rabelo, V. C., Weaver, K. B., Kovacs, J., \& Kemp, A. S. (2016). Baltimore is burning: Can I-O psychologists help extinguish the flames? Industrial and Organizational Psychology: Perspectives on Science and Practice, 9(3), 525-547.

Sackett, P. R., \& Wilk, S. L. (1994). Within-group norming and other forms of score adjustment in preemployment testing. American Psychologist, 49(11), 929-954.

Silva, J., \& Jacobs, R. R. (1993). Assessing the impact of increased selection of minority applicants on performance and monetary utility. Journal of Applied Psychology, 78(6), 591-601.

Sim, J. J., Correll, J., \& Sadler, M. S. (2013). Understanding police and expert performance when training attenuates (vs. exacerbates) stereotypic bias in the decision to shoot. Personality and Social Psychology Bulletin, 39(3), 291-304.

Smoktunowicz, E., Baka, L., Cieslak, R., Nichols, C. F., Benight, C. C., \& Luszczynska, A. (2015). Explaining counterproductive work behaviors among police officers: The indirect effects of job demands are mediated by job burnout and moderated by job control and social support. Human Performance, 28(4), 332-350.

Wright, P. M., \& McMahan, G. C. (1992). Theoretical perspectives for strategic human resource management. Journal of Management, 18(2), 295-320. 